\title{
Site Visits in Family Medicine: Stakeholders Perspectives on How Site Visits Can Be Improved to Maximize Preceptor Support and the Quality of Medical Student and Resident Supervision
}

\author{
Colla J. MacDonald ${ }^{1 *}$, Edward Seale ${ }^{2}$, Douglas Archibald ${ }^{2,3}$, Madeleine Montpetit ${ }^{2}$, \\ David Tobin $^{2}$, Michael Hirsh ${ }^{2}$, Martha McKeen ${ }^{3}$ \\ ${ }^{1}$ Faculty of Education, University of Ottawa, Ottawa, Canada \\ ${ }^{2}$ Department of Family Medicine, University of Ottawa, Ottawa, Canada \\ ${ }^{3}$ Bruyère Research Institute, Ottawa, Canada \\ Email: ${ }^{*}$ cjmacdon@uottawa.ca
}

Received April 23 ${ }^{\text {rd }}$, 2013; revised May 24 ${ }^{\text {th }}, 2013$; accepted May 31 ${ }^{\text {st }}, 2013$

\begin{abstract}
Copyright (c) 2013 Colla J. MacDonald et al. This is an open access article distributed under the Creative Commons Attribution License, which permits unrestricted use, distribution, and reproduction in any medium, provided the original work is properly cited.
\end{abstract}

\begin{abstract}
In 2012, the Department of Family Medicine at the University of Ottawa conducted a study to identify stakeholder's perspectives of site visits and how they can be improved to support preceptors and provide the best learning experience for medical students and residents. Two data sources were utilized to address the research questions: interviews with stakeholders (both focus group and individual interviews) and online surveys with preceptors. The findings assert that establishing a process for site visits to maximize preceptor support and the quality of medical student and resident supervision is a complex process. Perceptions of quality site visits for all stakeholders were strongly linked to: 1) having clear expectations; 2) making site visits a priority and supplying the necessary support and resources; 3) supporting preceptors to be better teachers; 4) the quality and timeliness of preceptor feedback from residents and medical students; 5) involving the medical student and resident in the site visit process; and 6) an integration and collaboration among curriculum, faculty development and evaluation resources. As researchers continue to build site visit recipes based on theory and reflection of practical experiences, the resulting insights will enable all stakeholders in family medicine programs to make more informed decisions to positively impact the quality of the site visit experience, support preceptors in being better teachers and improve the quality of the supervision of residents and medical students. This study takes one step toward building a broad base of theoretical knowledge informed by practical experiences on site visits.
\end{abstract}

Keywords: Site Visits; Family Medicine; Preceptor; Resident; Medical Student; Rural Community Site; Urban Community Site; Quality Standard

\section{Introduction}

As family medicine programs across Canada continue to grow and accept more medical students and residents in response to a shortage of family physicians, finding sufficient medical educators to provide effective learning experiences has become an ongoing challenge. As a result, Canadian medical schools have been expanding both undergraduate clerkship and postgraduate rotations into rural and community medical offices, clinics and hospital settings. A study by Bianchi, Stobbe and Eva (2008) demonstrated that medical students and residents who learn in rural and community environments are in no way experientially disadvantaged. First, community and rural medical clinics and offices typically encounter a wide variety of patients with complex issues and problems and therefore expose learners to a broad range of patients and rich learning experiences. Second, students and residents in rural and community settings claim close relationships with preceptors, a lot of hands-on opportunities and involvement, and experiencing

${ }^{*}$ Corresponding author. continuity of care. Finally, early exposure to rural community settings during clinical education increases the likelihood that these learners will stay and practice medicine in these underserved areas helping to correct the family physician mal-distribution in rural communities (Bianchi et al.; Curran \& Rourke, 2004; Denz-Penhey et al., 2005; Veitch et al., 2006).

\section{Challenges}

Supporting community and rural preceptors to ensure they are well equipped with exceptional clinical and pedagogical skills to provide excellent learning experiences for medical students and residents has become a formidable challenge for academic departments. While many community and rural based preceptors often find great satisfaction from teaching, supervising a learner in these environments can be demanding. The presence of medical learners can detract from the efficiency of a physician's office (Latessa, Beaty, Colvin, Landis, \& Janes, 2008; Sargent, Osborn, Roberts, \& DeWitt, 1993). Similarly, Pololi and Knight (2005) outlined challenges preceptors face 
related to the "changing nature of the current health care environment" including increased administrative and clinical responsibilities coupled with "reductions in time and collegial support for scholarly activity and teaching” (p. 866).

\section{Site Visits Solution}

Site visits are one mechanism employed by family medicine programs to offer support to preceptors and monitor quality control of the teaching experiences for medical students and residents in community and rural sites. Suzewits (2002) outlined the purpose of the site visit in ten objectives. In summary Suzewit suggests the site visit process involves 1) the assessment of the learner's progress in the clinical setting, 2) conducting a tour of the learning environment, 3) providing a forum for introductions (the preceptor to the departmental staff and vice versa), 4) educating and informing preceptors of new teaching methods and tools, 5) supporting ongoing dialogue regarding preceptors needs and departmental initiatives, 6) evaluating the resident's performance and suggest effective feedback options to the preceptor, 7) providing rotation specific feedback to the medical student or resident, 8) to obtain preceptor opinion or feedback concerning departmental policies or strategies, 9) to find resolution to problems involving a number of issues including finances, professional or personal issues and 10) career planning. Moser, Dorsch and Kellerman (2004) describe the site visit process as having the propensity to eliminate the "town-gown syndrome" and build "ivory bridges not ivory towers". Thus, a goal of the site visit process is to act as a mechanism to increase cohesion and promote a sense of inclusiveness throughout the entire faculty population.

Stearns, Hemesath and Londo (2000) explain that "for each precepting experience, the sponsoring department or program should provide a set of explicit and accomplishable goals, objectives, and expectations” (161). In addition to relaying important departmental expectations and policies, the site visit allows for the development of a mentor-mentee relationship between the preceptor and the academic staff performing the site visit. Typically the site visit involves a dyadic mentorship model (one preceptor with one resident) although some programs have developed collaborative mentorship models involving groups of preceptors who form a supportive network where ideas are shared and issues are resolved collaboratively (Pololi \& Knight, 2005). According to Bhagia and Tinsley (2000) the mentor-mentee relationship is ideally characterized by support, investment and inspiration. Mentorship can aid preceptors in clarifying their value as an educator, planning their academic career, developing useful relationships and pedagogical skills, and providing incentive to continue in academia (Pololi et al., 2002). Peer coaching is another effective form of mentorship that can involve co-teaching and the enabling of independent preceptor learning (Steinert, 2005).

Feedback is an important aspect of mentorship and peer coaching and a key component of the site visit process. Steinert et al., 2006 have found evidence suggesting "systematic and constructive feedback [to preceptors] can result in improved teaching performance” (p. 519). Elzubeir and Rizk (2002) called for increased focus on formative approaches to faculty evaluation that include regular feedback and opportunities for faculty development and mentoring. Langlois and Thach (2003) suggested the site visit process cater to many different types of preceptors with varying levels of clinical and educational ex- perience. Wilkerson and Irby (1998) define four different stages of preceptor involvement in educational careers: 1 ) entry level teachers who are refining their skills and orienting to academic values, responsibilities and expectations; 2) teachers with greater pedagogical skill and content knowledge; 3) educational leaders who may direct programs; 4) teacher-scholars who approach educational issues of process and reform. Those who facilitate site visits must be equipped with an array of skills necessary to cater to the needs of many different preceptors. Chew et al. (2003) recommended the development of multifaceted strategies while Malik et al. (2007) suggested better training for site visit facilitators and increased administrative and financial support to ensure site visits are well planned, efficient and effective.

\section{Purpose of the Site Visit}

Along with expanding Canadian Family Medicine programs comes the need to develop monitoring processes and protocols for decentralized teaching environments to ensure quality learning experiences that meets the College of Family Physicians of Canada's (CFPC) accreditation standards. Bianchi et al. (2008) elaborate:

\begin{abstract}
... finding acceptable methods of [continuous quality improvement] CQI of community-based teaching opportunities is a recurring theme in the literature; however, authors have not described a standardized strategy for program administrators to design, implement, or monitor the usefulness and acceptability of these CQI programs (p. 466).
\end{abstract}

Although site visits are an accreditation requirement mandated by the CFPC, the site visit protocol appears flexible and left to the discretion of each Department of Family Medicine (DFM). At the University of Ottawa (U of O) DFM, site visits are designed to have a faculty representative visit the preceptor for approximately one hour (usually over lunch), every two years. The purpose of the site visit is not to 'police' the preceptor but rather to provide support, resources and teaching strategies so preceptors are equipped to provide the best possible learning experience to the medical student or resident.

However, the faculty representatives at the DFM at the $U$ of $\mathrm{O}$ expressed concerns regarding the effectiveness of the site visit. Moreover, faculty reps reported they suspected many preceptors shared their concerns. Therefore, the purpose of this research project was to first, document stakeholders perspectives of the state of site visits in the DFM; and second, to solicit feedback from stakeholders on how site visits can be improved. By sharing our experiences, we hope that other DFM can draw from our suggestions and lessons learned.

\section{Methods}

The following research question served as a guide to obtain an understanding of the current state of site visits in the DFM and how they can be improved, "How can the Department of Family Medicine urban community and rural community site visits be improved to maximize preceptor support and the quality of medical student and resident supervision?” Four subquestions assisted in obtaining the answer to the overarching question:

- How do stakeholders describe the purpose of site visits?

- How do stakeholders describe the strengths of site visits? 
- How do stakeholders describe the shortcomings of site visits?

- How do stakeholders suggest site visits could be improved? Two data sources were utilized in this research project to address the research questions: interviews with stakeholders (both focus group and individual interviews) and online surveys with preceptors. Stakeholders were identified by the three faculty representatives and included the preceptors in urban community and rural practices, the two co-directors of site visits, the current interim chair who formerly was responsible for site visits in the DFM undergraduate program, and the site coordinator who is an administrator who supports the organization of the site visits. All preceptors in this study had supervised post graduate residents which require supervising a resident for two years. Some of these residents but not all had also supervised medical students for one month rotations or clerkships.

\section{Focus Groups and Interviews}

Seven interviews were conducted with site visit stakeholders (three individual and four focus groups) with a total of fourteen participants. The fourteen participants included ten preceptors representing both rural and communities teaching sites, two co-directors of site visits in the postgraduate program, the interim chair of the DFM (who was a former faculty site visit faculty advisor in the undergraduate program) and the coordinator of site visits. Preceptor experience ranged from two to twenty years. The three individual interviews lasted an average of 40 minutes and the four focus group interviews lasted an average of 60 minutes. All interviews were audio recorded and transcribed verbatim. For a copy of the interview protocol, see Appendix.

\section{Surveys}

The purpose of the online survey was to obtain preceptors' perspectives on the research question from a broader population than the focus group interviews permitted. A brief survey was developed which included (four demographic questions and 10 open-ended questions). The survey was housed on Survey Monkey ${ }^{\text {TM }}$. All rural and community preceptors $(\mathrm{N}=65)$ were sent the survey. A total of 14 preceptors completed and returned the surveys representing a response rate of $22 \%$.

A reminder email was sent one week following the first email. A total of 14 preceptors completed and returned the surveys. There was an even split of urban community preceptors and rural community preceptors. Ten of the preceptors had five or fewer years teaching experience and only one had more than 20 years. Eight of the 14 preceptors had supervised five or less residents in their careers and eight had supervised more than 10 medical students.

\section{Findings from the Focus Groups, Individual Interviews, and Surveys}

Qualitative data analysis was guided by Merriam (1998) and, Bogdan and Biklen (1998). The interview transcripts were checked for accuracy by the researcher listening to the audio recording (mp3 file) and comparing them to the transcribed text. Open coding of the text was then performed by hand. After a preliminary list of codes were developed the transcripts were coded a second time to group common codes together to form themes. The coding was reviewed several more times to ensure that no new codes emerged from the data. Once the themes reflected "the recurring regularities or patterns in the study" (Merriam, 1998: p. 181), and the researcher was satisfied the themes reflected the needs and views of the participants, the data were assigned to categories to provide rich, detailed, and comprehensive information that would answer the research questions.

Relevant information from the emerging themes were used to weave a story from multiple stakeholders' perspectives portraying the current state of site visits in the DFM and how site visits may be revised to support preceptors in providing a positive learning experience for residents and medical students. Direct quotations are used throughout this paper to allow participants' voices to be heard and to obtain objective evidence regarding the participants' perceptions of the site visits. All interview participants were provided a copy of the qualitative data analyses to ensure the interpretation was according to their intentions and perspective. Interview participants were provided an opportunity to adapt, remove or elaborate on any quote or text that misrepresented their perspective. One preceptor made minor edits to the analysis report.

The findings from the interviews are organized under the sub research questions purpose of the site visit, strengths, shortcomings and improvements.

\section{Purpose of the Site Visit}

The five themes that emerged regarding the purpose of the site visits were: Teaching Environment; Support, Preceptor's Experience, Affirmation and Quality Assurance.

\section{Teaching Environment}

When asked about the purpose of the site visit, both co-directors and the preceptors agreed one purpose is to make sure preceptors have the right layout and teaching environment to accommodate a resident or student. There appeared to be a common understanding among stakeholders that having the right layout implies the teaching environment is physically and operationally appropriate and conducive to teaching and learning. For example, a proper layout would consider the office layout, patient profile, staff mix, resources available). However, no clear description of an appropriate layout for effective teaching and learning currently exists in the program. One co-director elaborated:

The purpose has been based on what has happened in the past ... visit usually over lunch for approximately an hour. Inspect the place of work that the resident is in. Then sit with the preceptor and discuss how things are going with the resident. We talk to him about what's happening with faculty development, new things happening in the department, how we can help.

Preceptor's perspective of what occurs during a site visit was similar to the co-directors.

We tell them how our practice has changed. How many physicians we work with? Do we offer OB [obstetrics]? Minor procedures? How many nurse practitioners, dieticians we have? Who we work with? What we offer.

Similarly, preceptors elaborated both in the interviews and on the surveys that the site visits provide an opportunity to have fresh eyes review their teaching site and to ensure the sites are 
set-up for teaching residents.

\section{Support}

Interview participants agreed creating a liaison between the DFM and the community and rural teaching sites is one purpose of the site visit. The site coordinator pointed out the site visit allows for a sense of connectedness between the DFM and the community and rural practices. "There is a tendency for community preceptors to feel quite isolated. Having the codirectors physically visit their different community sites allows for the preceptors to feel more a part of the department”. Although all interview participants agreed that one of the purposes of the site visits was to liaise, there were mixed perceptions from preceptors regarding the amount of support they receive. An experienced preceptor revealed she felt the DFM was very supportive when she had a resident in difficulty.

My resident needed more exposure to acute care community practice. So I sent the individual to the urgent care clinic for a month. To pick a colleague with a specific practice profile or specific learning setting and have our residents go there to do extra work is very valuable.

Other preceptors felt the support was available from the DFM if you knew how to access it. One preceptor shared, "Sometimes the support is very good, but you have to know how to search it out". A second preceptor shared, "The support is not there if you don't go looking. But it is amazing what they will do for people".

\section{Preceptor's Experience}

The co-directors stipulated if the preceptor has never had a resident or medical student before, or they are inexperienced, the purpose of the site visit is different than if the preceptor has years of experience supervising residents and/or students. Similarly preceptors pointed out that there could be a difference in the purpose of the site visit if the preceptor has a resident or student in difficulty or if the preceptor continually receives poor evaluations from the resident or student. "If they are going along swimmingly and there is no problem then why bother them? Whereas Joe Blow with his third sub-par evaluation, the site visit is a forum for communication".

\section{Affirmation}

For one preceptor a purpose of the site visit is affirmation that they are doing a good job. Another preceptor explained, "I didn't really gain anything from the site visit per se, except for a confirmation that what I was doing was a reasonable type of practice and the training I was doing was appropriate”. The interim chair described the purpose of site visits as:

... part PRs part feedback... validate by showing up, waving the flag, giving them credit for what they do ... giving feedback; letting them know what is going on at the university, trying to offer some sort of faculty development ... There are many differing thoughts in this statement ... needs to abridge to assure desired focus.

\section{Quality Assurance}

All stakeholders identified site visits as a quality standard mechanism to ensure consistency across teaching sites. Similarly, the site coordinator reported that one purpose for site visits is to safeguard that all residents and medical students have the same learning opportunities. The site coordinator explained site visits were also necessary for accreditation and to ensure quality. "The department via the co-directors need to have a good understanding of who their preceptors are and the learning opportunities their residents are exposed to at the various teaching sites”.

\section{Strengths}

Two themes emerged regarding the strengths of site visits: Communication and Enjoyment.

\section{Communication}

According to the co-directors, a strength of site visits is providing a 'face' to the DFM. The co-directors believe preceptors feel respected and valued when representatives from the DFM take the time to visit. "There is a sense of mutual respect which is important to foster relationships". Similarly, the interim chair suggested the site visit was, “... personal face-to-face time with someone from the university so you connect and offer an element of feedback [based on learner evaluations]". One survey respondent indicated, "[The visit] gives me as a community preceptor the ability to interact directly with the community director and give and receive direct feedback".

The co-directors reported site visits provide a mechanism to share teaching tips between and among sites. They stated they pick up effective teaching strategies from one site and communicate these strategies to other sides. One co-director shared, "Sometimes we pick up things that are very useful and we can say 'we visited so and so and they dealt with your problem this way'. So actually going there is a good way of passing it on". Some preceptors agreed that an advantage of the site visits was sharing knowledge among sites. In the words of one preceptor, "It is cross-pollinating knowledge between different sites".

\section{Enjoyment}

When asked why they take residents and students the preceptors didn't hesitate to reveal they do it because they enjoy it.

We enjoy it. If I didn't like it, I would have probably tried it for two years and then said "I am out". If my first few residents were poor then I probably would have bailed because they could ruin things.

Another preceptor reported she took residents and students because she loved teaching. She elaborated, "it is fun, challenging, rewarding and keeps you on your toes”. A third preceptor stated she took residents because, “... she is a better physician for having had residents”. Preceptors elaborated that having a resident or student also provides them with a break from their routine. "Like anything else even after the challenge, I think most of us sign on because we enjoy it”.

The interim chair supported that those who consistently take a resident or student, do so because they enjoy it and love to teach. "I think the people who have chosen to be full time teachers ... are self-selected. These are people who like to teach, like the idea of having a resident around, like to be involved with the university”.

\section{Shortcomings}

The eight themes that emerged regarding the shortcomings of the site visits were: Expectations; Co-directors Role; Scheduling; 
Compensation; Time; Inconsistency, Resources and Preceptor Assessment.

\section{Expectations}

Preceptors pointed out what is not made clear when taking a resident/student is the amount of paper work and time required to do evaluations.

What you don't know going in is all the evaluations required. You have to go to SOOs [structured office oral exam]. There is an expectation that you go to ITER [in-training examination report]. They come and do site visits, department meetings. That should be told ahead of time so there are no surprises.

There does not appear to be clarity on expectations for seeing patients during the resident's rotations. The resident's schedule appears to be organized by the preceptor. Some preceptors reported they see exactly the same number of patients whether or not they have a resident or student. Other preceptors said they try to book fewer patients when they have a resident. One preceptor explained, "I try to book a little less especially when my resident is on their half-day back”. Other preceptors reported they set up a schedule for learners to have their own patients. One preceptor suggested that more direction on how best to schedule patients while supervising a resident would be helpful. "One thing they [co-directors] have never asked me and I always thought they should is how many people I am seeing per hour and whether there is a volume that might not be the best for a teaching environment”.

The interim chair pointed out that benchmarks for what residents and students should know at various points in their program are not made available to guide preceptors in their teaching. Preceptors reported they would like to receive a manual or have a web page they can go to outlining the DFM's expectations of them. Another preceptor clarified that she attended an orientation session but it was six months into the whole process when she had already been teaching.

\section{Co-Directors Role}

The co-directors admitted they sometimes doubt the value of conducting site visits as they do not perceive themselves any more knowledgeable or proficient at teaching residents and students than many of their peers. The co-directors were humble sharing they are not expert teachers, and other than creating a liaison with the DFM they too questioned the value of the site visit. Similar to what the preceptors said, the co-directors revealed that when the preceptor is experienced and has no issues, the site visits seem a little trite and somewhat superficial. One co-director stated, "We [the co-directors] feel we are equal to the preceptors. So there is the imposter syndrome. To fulfill their [preceptors] needs maybe we are not the right people”. One of the co-director explained his dilemma with the site visits:

For some I get the feeling it is really good. I have made a connection and they understand what is going on. For the ones that have been doing this for a long time, I feel bad I'm taking their time because I don't know how much they are getting out of it.

The co-directors stated the heart of the problem is that the preceptors are their colleagues. In some instances they have worked together or were classmates. In most situations, codirectors didn't feel they were in a position to help their colleagues become better teachers. "When the discussion comes around to setting learning plans, I don't know how to do that. I am absolutely not a resource to them. Some things I can [help], or I can refer them to somebody”.

\section{Scheduling}

When asked what the shortcomings of the site visits were, the co-directors explained that coordinating schedules was complicated and pinning down preceptors to commit to a time for a visit was often a challenge. "I wish they [site visits] were consistent and scheduled. It always seems like a barrier and I don't know on whose part. Scheduling of the site visits needs to be prioritized if it's felt to be a priority”. Scheduling issues were identified by six of the fourteen survey respondents

\section{Compensation}

For a few preceptors, one complaint communicated regarding site visits was that the stipend they receive for having a resident/student doesn't cover their costs. One preceptor explained that she is on salary. She does not receive the stipend but rather it goes back into the centre. For most preceptors teaching is not about being remunerated. In the words of one preceptor, "It is not the compensation. It is the wasted time because the time in your day is so valuable. It is I can't believe they have spent an hour to do this. I sit and go 'everything's fine'”.

\section{Time}

One of the biggest drawbacks of site visits for everyone involved was the time they demand. The co-directors are physicians who run their own family medical practice. Their director position is one day a week and during that time they are often required to attend meetings at the DFM. The co-director's identified meetings and administrative responsibilities as a barrier to conducting site visits.

The meetings get in the way of site visits. Meetings that have nothing to do with community doctors. Sitting on advisory committees and executive committees probably take on average about half the working day.

The co-directors reported they could be doing a better job if there were fewer meetings and administrative responsibilities attached to their role. "I would like to be on the phone with them, out visiting them, seeing how things are going, asking them if they have problems, reacting if there are problems. Otherwise they get fed up".

Some preceptors complained the site visit took time away from their patients. Others felt that when they did spend time communicating things that could change, nothing happened. In the words of one preceptor, "Time consuming if we are just going through a checklist with no change. Every year we give them ideas of what needs changing and then nothing happens”.

The surprise for some preceptors was that in addition to everything else they found out after the fact that they were responsible to supervise a research project. In the words of one preceptor:

I found out from my resident that they can do a research project with you and that is more work. That was not in the contract. I am sitting at home on my computer on Sat- 
urday night doing this online course to get this certificate to submit to the university so I can supervise him. That is above and beyond.

Preceptors stated that five years ago the research projects became "way too big". A second preceptor agreed and pointed out that now the research project required the resident to do a review of literature on top of everything else. Another preceptor said he didn't mind the project was big but what she found frustrating was, "all the hoops they have to jump through now".

\section{Inconsistency}

One issue broached by several preceptors and supported by the site coordinator and the interim chair was that the community and rural preceptors have a very different experience than preceptors who teach in the units. In the words of the site coordinator:

The first priority of a community physician is their practice. A resident can detract from their business because they need to spend more time with the resident. It has an impact on their finances. Unit preceptors have a different funding arrangement. It is just a different situation.

Preceptors discussed that it is often extremely time consuming to have an International Medical Graduate (IMG). Preceptors suggested that IMG residents require a lot of one-on-one supervision and support they are more likely to receive in the community than in a unit. "If they [residents] are in a unit with a group of preceptors things get lost and no one takes ownership or responsibility the way you do one-on-one with your resident”. One preceptor suggested a reason she devoted so much time to supervising residents was to ensure her patient's safety, "I am just obsessive that they're going to do something wrong and hurt my patient”.

\section{Resources}

When asked what resources the preceptors are currently receiving, the co-directors reported they provide the preceptors with a list of faculty development sessions available, the names of the people in the DFM who might be helpful to them and they answer questions based on preceptor needs. "We try and provide them with that sort of information". The site coordinator elaborated on the resources provided to Post Graduate full time preceptors:

Community preceptors get funding annually for professional development. They can receive funding from the department for AV equipment. If they have a resident they are compensated. They are invited to faculty development sessions, curriculum development events, the faculty retreats and dinners. They have funding for attending conferences. There are perks for sure.

All preceptors who have full time residents are eligible to have video equipment supplied to them by the DFM. One preceptor had the equipment but admitted he rarely used it because it required getting the patients permission. Those preceptors that used the video equipment were adamant that it was a valuable teaching tool. One preceptor explained:

It [the video] is a fantastic tool. The minute I am in the room the dynamic between the resident and the patient changes. We sit down at the end of the day and review two or three. They pick up on things they need to change.

The preceptors stated that the video equipment made it easier to provide the resident with constructive feedback. When the residents saw their behaviour, preceptors felt they better understood the message they were trying to communicate. One preceptor shared, "If you just tell them something they can be defensive. When they can actually see it on videotape, you say to them "do you notice how often you are doing such and such, what do you think about that?”

Preceptors suggested they needed to share resources and information about supervising residents and students with one another. One experienced preceptor suggested, "We need to share that information to a greater degree”.

\section{Preceptor Assessment}

During the site visits, the co-directors provide the preceptors with evaluations from previous residents and students if they have any available. However, the evaluations are not made available to preceptors until a year after the resident graduates. In reality, this can be up to three years after the evaluation was completed.

All preceptors expressed their dissatisfaction with the way they receive feedback from residents and students. Preceptors all strongly agreed that they do not receive enough feedback and the feedback they do received comes far too late. "If I have a deficiency in my office, no one knows it better than my resident". One preceptor stated, "I strongly object to it being three years after the fact ... we are adults. We should be getting feedback just like we are giving our residents feedback. ... Three years later ... it is too late ...” A preceptor who had supervised approximately twenty residents and twenty students over a twenty year period revealed that during that time she had only received "I think three [assessments] in my lifetime". A second preceptor shared she had supervised thirty residents and twenty medical students over a twenty year period and reported she had received "Maybe four or five".

Several preceptors stated they do not like the one45 evaluation system used by the DFM to assess residents. They explained that in this system they are required to search for their resident's evaluation forms and suggested the forms should be sent to them automatically. One preceptor pointed out another issue with the evaluations of residents. "I had a resident who didn't pass the exam this time. I hope if there had been red flags along the way. If there is a 2 out of 4 then the primary preceptor has to be informed".

\section{Preceptors' Recommended Improvements}

The final themes of recommended improvements for the site visits have been summarized in Table 1.

\section{Discussion}

All stakeholders agreed that the site visit process was a step toward overall program quality assurance. Similarly, Malik et al. (2007) found the site visit process to be an important CQI initiative with the potential to effectively evaluate distant community teaching sites. The findings from the this study also support Suzewits' (2002) allocation that a tour of the facilities during the site visit allows faculty representatives to become familiar with the types of learning settings that exist outside the large 


\section{J. MACDONALD ET AL.}

Table 1.

Recommended site visit improvements.

\begin{tabular}{|c|c|}
\hline Thematic Description & Quote \\
\hline DFM to prioritize site visits & $\begin{array}{l}\text {... if it is useful let's put our resources into scheduling it. Setting up the time to } \\
\text { make it value added so there is an educational experience with resources. }\end{array}$ \\
\hline DFM to provide clear expectations & $\begin{array}{l}\text { More time, set agenda according to the site's needs and the program directors } \\
\text { need to ensure we are following the college requirements. More frequent visits } \\
\text { when a new site is starting up. }\end{array}$ \\
\hline DFM to provide support for preceptors to become better teachers & $\begin{array}{l}\text { I have never really used the CanMeds curriculum to either learn or teach. Where do } \\
\text { you start? The obstetric population is my practice profile. How do I take this large } \\
\text { amount of information when only twenty percent applies to me? }\end{array}$ \\
\hline Involve residents in the site visit & $\begin{array}{l}\text { The site visit is now like the parents talking about the kids without the kids having } \\
\text { any input. I think during a site visit the resident should be present at the very least" }\end{array}$ \\
\hline Alternative Strategies: teleconference and videoconference & $\begin{array}{l}\text { I like the Skype idea. Everybody has computers. You could talk for fifteen minutes. } \\
\text { Unless it was a new person }\end{array}$ \\
\hline Provide one support email for questions & $\begin{array}{l}\text { When you feel supported you don't feel isolated. You feel that it is worth the time } \\
\text { and effort you are putting in and that is very positive. }\end{array}$ \\
\hline Site Evaluations & Give advance notice of what will be covered during the visit. \\
\hline
\end{tabular}

academic centres.

All stakeholders perceive site visits in their current structure are not as effective as they could be. One of the programmatic shortcomings that surfaced was that community/rural faculty members often feel that they are not given adequately laid out expectations for teaching and that their responsibilities are not clearly defined at the outset of their preceptorship. Stearns et al. (2003) identify this as a problem that is prevalent in most academic medicine community settings. "Vague and global objectives are not helpful and do not maximize the learning opportunity for those involved” (161). Stearns et al. (2000) emphasized the need for clinical departments to clearly outline their vision for preceptorship at the outset of an educator's career.

Despite the finding that some preceptors didn't find the site visit to be particularly useful, the University of Ottawa team found that some preceptors simply appreciated being recognized for their work as educators. This finding is in accord with Suzewits', 2002 idea that an important aspect of the site visit is the opportunity it gives departmental leaders to thank their educators in person. For the most part, the opportunity for informal discussion was valued as was the opportunity for remote faculty members to be apprised of issues that emanated from the urban hub of the program such as curriculum reform, policy changes etc. This is in line with Moser et al. (2004) findings that demonstrated that community based faculty members typically appreciate knowing departmental leaders and staff on a "firstname basis” (p. 317). Lowenstein et al. (2007) also report that faculty members often appreciate feeling a part of the institution with whom they are affiliated and that a failure on the part of the institution to nurture ties with academic staff can lead to career dissatisfaction and attrition.

All stakeholders alluded to the idea that site visits should not be a one size fits all operation. Both the co-directors and preceptors suggested the purpose of the site visit should and does change based on the experience and competency of the preceptor. Likewise, Malik et al. (2007) noted the importance of creating teacher specific materials for site visits to ensure there are relevant for the preceptor involved. The findings of this study highlight the challenge inherent in running a site visit program that caters to diversity among the faculty ranks. Wilkerson and Irby (1998) identified levels of educational careers that require very different types of professional support and mentoring. However Pololi and Knight (2005) argued that mentorship and collegial communication can be extremely valuable "regardless of status, position, or level of expertise” (p. 868). I would mention the role of collaboration between site visit facilitators and Fac Dev team.

The co-directors revealed that they have a bit of the "imposter syndrome” because they do not feel they are more qualified than many of their experienced peers at teaching and were inherently uneasy about the perception of site visits being a position of power. Malik et al. (2007) also found their site visit facilitators expressed discomfort with the idea that they were "policing" their peers. Their solution was to develop a site visit policy document that described the purpose of and expectations for the site visits.

The co-directors of site visits reported they would like to see their role involve fewer faculty meetings so they can devote more time to supporting preceptors. Moreover, they want the DFM to put more resources into scheduling visits, prioritizing and making site visits more effective. Moser et al. (2004) also identified the freeing up of time for academic faculty to conduct site visits as well as scheduling with preceptors at distant sites as being the two main challenges associated with the site visit process. Similarly, Malik et al. (2007) emphasized the need for strong administrative and financial support for coordinating site visits.

Preceptors reported they enjoyed being a preceptor, loved teaching and the challenge it brought to their practice. This is in line with Latessa et al. (2008) who reported that community physicians found the opportunity to introduce learners to working in the community setting to be particularly satisfying.

Community and rural preceptors often remarked that their experiences differed from those of unit-based preceptors. The site visit process must adapt to the needs of the community/rural preceptor group in order to be effective. Moser et al. (2004) state the fixation on the tangible aspects of the site visit is often ineffective. The solution may be for faculty reps to focus more on the facilitative skills and methods that departmental leaders utilize in response to the feedback they receive during the visits so they are prepared with adequate resources to respond to issues that arise. 
All preceptors were open to having site visits if they were structured to help them become better teachers. The preceptors articulated they need to "share information and resources". Steinert et al. (2006) cited the importance of collegial support and the formation of networks for the mutual exchange of information and ideas as well as the importance of institutional support for community based faculty through faculty development. Moser et al. (2004) cited the importance of delivering individualized faculty development opportunities for seldom reached faculty members (p. 318). Similarly, Malik et al. (2007) called for site visit programs to equip facilitators with the knowledge and tools to bring faculty development offerings to dispersed faculty members. Suzewits (2002), Malik et al. (2007) and Moser et al. (2004) called for the inclusion of faculty development in the site visit process as an effective strategy for reaching distant and often disconnected faculty members.

How and when preceptors receive feedback from residents were the biggest criticisms preceptors associated with of the site visit. Lowenstein et al. (2007) found that a lack of timely and constructive feedback from departmental leaders can have devastating impacts on the morale of faculty members in academic medicine. The University of Ottawa data is congruent with these findings and suggests a need to improve the way in which community/rural preceptors receive feedback on their teaching (Steinert et al., 2006).

A few preceptors suggested having the resident involved in the site visit in some capacity would be an alternative site visit structure worth exploring. Suzewits (2002) included interactions with learners in his description of the purposes of a site visit. Similarly, Moser et al.'s (2004) approach to the site visit process calls for facilitators to provide direct feedback to learners and also provide individualized faculty development and professional feedback to preceptors.

\section{Conclusion}

The findings from this study highlighted congruency between and among stakeholder's perspectives of site visits and how they can be improved to support preceptors and provide the best possible learning experience for medical students and residents. The findings also gleaned results that are in line with existing literature on the site visit process. In particular, the site visit process as a mechanism to ensure a programmatic quality standard in the community setting, to provide opportunities for faculty development, to disseminate information on departmental and institutional affairs, to promote career development, to address issues with students or residents and to meet accreditation requirements are all well-established objectives of site visits as outlined by Suzewits (2002), Moser et al. (2004) and Malik et al. (2007). The areas for improvement, the strengths and possible solutions are also in line with current literature calling for the rationalization of site visit programs to make them more effective (Malik et al., 2007) and efficient for stakeholders as well as the call for more inclusion of faculty development (Moser et al., 2004; Malik et al., 2007; Steinert, 2005) and the shift toward a more interventionist stance (Suzewits, 2002) or the involvement of the learner in the process. The University of Ottawa study demonstrates a need to continually improve and monitor programs that aim to engage community and rural faculty members to ensure that they feel a part of the academic department with which they are affiliated.

Several of the preceptor's ideas and concerns that emerged in this study were not specific to how site visit can be improved but had far broader implications for how the entire DFM program could improve. Although all of the issues and ideas raised by the preceptors affect site visits, they are all encompassing program interrelated issues such as the evaluation process, timeliness of receiving feedback from residents, faculty development and the orientation process. Some of the concerns and issues have already been addressed and plans for responding to several others preceptors concerns are underway. For example, the site visit co-director's roles are to facilitate growth and maintenance of quality through their contacts and networking with preceptors. Responding to the feedback from this study, the site coordinators have worked out a system to make better use of their time so they are available to spend more time responding to preceptor's needs. Findings that emerged from this study have fuel the DFM approach to remediation and benchmarks for our own internal continual quality improvement. Standard questions and benchmarks are being created for quality assurance to ensure preceptors provide residents with direct observations, feedback well rounded patient profiles, and an effective teaching/learning environment. In response to preceptors feedback, the DFM has created a graded form for site visits that corresponds with preceptor's experience (new preceptor site visit; experienced teaching practice; situation where there is a learner in difficulty; and using experienced preceptors to teach others). The co-directors of site visits are also focusing on getting evaluation back to the preceptors more expediently.

A close working collaboration between the site co-directors and the co-directors of faculty development has evolved to address many of the concerns raised by preceptors in this study. A new tailored orientation has been organized specifically for the DFM to clearly outline preceptor's roles and make explicit procedures, available resources, and expectations. Processes and mechanisms are being initiated to have preceptors improve situations by taking ownership and empowering them to communicate and offer suggestions and solutions when they perceive a process isn't effective or effective. Blogs and open forums for providing feedback constructively and anonymously are being set up.

A grassroots initiative has been initiated to try to have preceptors come up with teaching solutions and share ideas and best practices. One consistent idea communicated by preceptor was they feel they learn best from one another. As a result one initiative that emerged as a result of the findings from the this study is "Teaching Tips at your Fingertips", where preceptors describe their tried and true teaching tips in a YouTube video. The video links are emailed and tweeted to their colleagues in order to share best practices. Having preceptors become more involved by sharing their teaching pearls that either link to evidence based practice or that emerged from experience will enhance the learning community and support system between and among the community and rural preceptors.

An Essential Teaching Skills program have been developed which consists of a series of four hour main pro $\mathrm{C}$ accredited workshops that address several of the teaching related concerns raised by preceptors in this study (how to deal with a student in difficulty, how to observe, evaluate and provide a resident with feedback and issues related to professionalism). Moreover, a follow-up focus group will take place with the same group of preceptors that participated in this study two years following the first focus group to solicit feedback on whether they feel things have improved and what still needs attention and improvement. 
The findings from this study suggest that effective site visits involve curriculum, faculty development and evaluation issues and all components need to work together in an efficient manner if the entire system is to be effective. Supporting preceptors to be better teachers emerged as a key factor that links these components into a responsive and relevant situational learning experience.

Given resource requirements and the degree of collaboration required to deliver effective site visits, it appears that a professional approach to site visits is essential. Site visits will not be effective if simply composed of a list of required ingredients of success. Rather effective site visits will require a recipe or framework whereby any site visit program can be carefully implemented, monitored and supported to succeed (MacDonald, Stodel, Farres, Breithaupt, Gabriel, 2001; MacDonald \& Thompson, 2005; MacDonald, Stodel, Thompson, \& Casimiro, 2009). Research must be ongoing to continually monitor and adapt the recipe and enable more deliberate application of strategies that lead to a quality site visit experience.

This study also illustrates the dynamic intersections between theory and best practices. Theory informs actions, and actions modify theories so that future actions grow out of what we have learned by experience and reflection (MacDonald \& Thompson, 2005; Thompson \& MacDonald, 2005). When preceptors perceive that theory makes good practice and good practice makes theory, the entire system will be energized. As researchers continue to build site visit recipes based on theory and reflection of practical experiences, the resulting insights will enable all stakeholders in a family medicine program to make more informed decisions to positively impact the quality of the site visit experience, support preceptors in being better teachers and improve the quality of the supervision of residents and medical students. This study is one step in helping to build a broad base of theoretical knowledge informed by practical experiences on site visits.

\section{Acknowledgements}

The authors would like to thank the busy preceptors who generously gave their time to participate in this study to improve the site visit program.

\section{REFERENCES}

Bhagia, J., \& Tinsley, J. A. (2000) The mentoring partnership. Mayo Clinic Proceedings, 75, 535-537.

Bianchi, F., Stobbe, K., \& Eva, K. (2008) Comparing academic performance of medical students in distributed learning sites: The McMaster experience. Medical Teacher, 30, 67-71.

doi:10.1080/01421590701754144

Casimiro, L., MacDonald, C. J., Thompson, T.-L., \& Stodel, E. J. (2009). Grounding theories of W(e)Learn: A framework for online interprofessional education. Journal of Interprofessional Care, 23, 390-400.

Chew, L. D., Watanabe, J. M., Buchwald, D., \& Lessler, D. S. (2003). Junior faculty's perspectives on mentoring. Academic Medicine, 78, 652. doi:10.1097/00001888-200306000-00022

Denz-Penhey, H., Shannon, S., Murdoch, J. C., \& Newbury, J. W. (2005). Do benefits accrue from longer rotations for students in Rural Clinical School? Rural Remote Health, 2, 414

Elzubeir, M., \& Rizk, D. (2002) Evaluating the quality of teaching in medical education: are we using the evidence for both formative and summative purposes? Medical Teacher, 24, 313-319. doi:10.1080/01421590220134169

Farell, S. E., Digioia, N. M., Broderick, K. B., \& Coates, W. C. (2004) Mentoring for clinician-educators. Academic Medicine, 11, 13461350 .

Langlois, J. P., \& Thach, S. B. (2003) Bringing faculty development to community-based preceptors. Academic Medicine, 78, 150-155. doi:10.1097/00001888-200302000-00009

Latessa, R., Beaty, N., Colvin, G., Landis, S., \& Janes, C. (2008) Family medicine community preceptors: Different from other physician specialties? Family Medicine, 40, 96-100.

MacDonald, C. J., Stodel, E. J., Thompson, T.-L., \& Casimiro, L. (2009). W(e)Learn: A framework for interprofessional education. International Journal of Electronic Healthcare, 5, 33-47. doi:10.1504/IJEH.2009.026271

MacDonald, C. J., \& Thompson, T. L. (2005). Structure, content, delivery, service, and outcomes: Quality e-learning in higher education. International Review of Research in Open and Distance Learning, 6. http://www.irrodl.org/index.php/irrodl/article/view/237/321

MacDonald, C. J., Stodel, E. J., Farres, L. G., Breithaupt, K., \& Gabriel, M. A. (2001). The demand-driven learning model: A framework for web-based learning. Internet and Higher Education, 4, 9-30. doi:10.1016/S1096-7516(01)00045-8

Malik, R., Bordman, R., Regehr, G., \& Freeman, R. (2007). Continuous quality improvement and community-based faculty development through an innovative site visit program at one institution. Academic Medicine, 82, 465-468. doi:10.1097/ACM.0b013e31803ea942

Moser, S. E., Dorsch, J. N., \& Kellerman, R. (2004). The RAFT approach to academic detailing with preceptors. Family Medicine, 36, 316-318.

Pololi, L. H., \& Knight, S. M. (2005). Mentoring in academic medicine. A new paradigm? Journal of General Internal Medicine, 20, 866870. doi:10.1111/j.1525-1497.2005.05007.x

Pololi, L. H., Knight, S. M., Dennis, K., \& Frankel, R. M. (2002). Helping medical school faculty realize their dreams: An innovative, collaborative mentoring program. Academic Medicine, 77, 377-384. doi:10.1097/00001888-200205000-00005

Sargent, J. R., Osborn, L. M., Roberts, K. B., \& DeWitt, T. G. (1993). Establishment of primary care community experiences in community pediatrician's offices: Nuts and bolts. Pediatrics, 91, 1185-1189.

Skeff, K. M., Stratos, G. A., Mygdal, W., DeWitt, T. A., Manfred, L., Quirk, M., Roberts, K., Greenberg, L., \& Bland, C. J. (1997). Faculty development, a resource for clinical teachers. Journal of General Internal Medicine, 12, S56-S63. doi:10.1046/j.1525-1497.12.s2.8.x

Stearns, J. A., Hemesath, K., \& Londo, R. A. (2000) Goal setting for community preceptorships. Family Medicine, 32, 161-162.

Steinert, Y. (2005). Staff development for clinical teachers. The Clinical Teacher, 2, 104-110. doi:10.1111/j.1743-498X.2005.00062.x

Steinert, Y., Mann, K., Centeno, A., Dolmans, D., Spencer, J., Gelula, M., \& Prideaux, D. (2006). A systematic review of faculty development initiatives designed to improve teaching effectiveness in medical education: BEME Guide No. 8. Medical Teacher, 28, 497-526. doi:10.1080/01421590600902976

Suzewits, J. (2002) Preceptor site visit. Family Medicine, 34, 240-241.

Thompson, T. L., \& MacDonald, C. J. (2005). Community building, emergent design and expecting the unexpected: Creating a quality eLearning experience. The Internet and Higher Education, 8, 233249. doi:10.1016/j.iheduc.2005.06.004

Veitch, C., Underhill, A., \& Hays, R. B. (2006). The career aspirations and location intentions of James Cook University's first cohort of medical students: A longitudinal study at course entry and graduation. Rural Remote Health, 6, 537.

Wilkerson, L., \& Irby, D. M. (1998). Strategies for improving teaching practices: A comprehensive approach to faculty development. Academic Medicine, 7, 387-396. doi:10.1097/00001888-199804000-00011 


\section{Appendix}

\section{Focus Group Interview Protocol}

- Use either SI (MKS) or CGS as primary units. (SI units are encouraged.) English units may be used as secondary units (in parentheses). An exception would be the use of English units as identifiers in trade, such as "3.5-inch disk drive".

- What is your current position?

- How many community/rural clerkships have you experienced/supervised?

- How many community/rural resident rotations have your experienced/supervised?

- What is the purpose of the site visit?

- What are the strengths of the site visit?

- What are the shortcomings of the site visit?

- When was the last time you had a site visit?

- How often would you like to have a site visits?
- What more could the DFM do to support you in your role as a community/rural preceptor?

- What more could the faculty rep do to support you in your role as a community/rural preceptor?

- What resources do you currently receive during site visit?

- What resources would you like to see during the site visit?

- Are you clear on what is expected from you as a medical student/preceptor/preceptor?

- What is the current protocol for the site visit?

- How could the site visit be improved?

- Do you have any other comments that may be useful to us in improving the site visit as a mechanism to support you in your role as a preceptor and ensure the medical student/resident have a positive experience? 